\title{
Disruptive Technologies supporting Agricultural Education
}

\section{Kim Bryceson}

School of Agriculture and Food Science, The University of Queensland, Australia.

\begin{abstract}
This paper looks at a number of different technologies that are being used currently in agricultural education at The University of Queensland (UQ), Australia through the lens of 'disruption' as a positive force. The paper describes a number of tools and systems that have been developed, tested and implemented to engage students and provide an interesting, educative interactive experience at UQ. These tools include Internet of Things (IoT) multisensory mesh networks and associated data dashboard developments for biophysical monitoring, drone technology design and build for agricultural management, and augmented reality simulations as blended learning experiences. These tools have been used in teaching in 2017, 2018 and 2019 and have been evaluated positively for student engagement and the learning value to students of the tools.
\end{abstract}

Keywords: Internet of Things; drones; data dashboards; augmented reality 


\section{Introduction}

Young people are difficult to encourage into agriculture and related educational areas, because the industry sector is perceived as labour intensive, non-academic and lowly paid. This is frustrating to the agrifood industry generally, and also to educators in the sector. A potential solution is to use digital technologies as a means of innovating legacy systems in the sector and to use these same digital technologies as a 'disruptive agent' to change the way agricultural education is undertaken and increase student engagement.

\subsection{Technology as a 'disruptive' agent}

A disruptive innovation or technology is one that can 'disrupt' or 'overturn' traditional business methods and practices and which in the long term, can leads to the creation of new 'ground-breaking' products (Christensen \& Overdorf, (2000); Millar, et al. (2018).

Over the last decade, disruptive technologies in the form of the Internet, mobile computing (including social media for marketing purposes), Internet of Things (IoT) technologies to collect and transmit real time data, the use of cloud computing to facilitate the analysis of such generated big data and robotics to make use of the data, have been identified as having impacted the agrifood industry in an unprecedented way to create and capture value across the whole chain (Bryceson, 2006; Lehmann, et al. 2012; Bryceson \& Yaseen, 2018).

ICT technology as a disruptive agent in education, particularly in higher education, has been much discussed starting in the late 1990s with the advent of the internet and then onwards with the number of articles discussing different aspects of 'disruptive' technologies increasing significantly. For example Archer et al. in 1999 identified that the internet was likely to be a disruptive technology in higher education generally with learning materials delivered 'online' via the internet; Sharples (2003) talked about using mobile phones as tools for learning; Garrison \& Kannuka (2004) discussed the notion of blended learning as "[combining] text-based asynchronous Internet technology with face-to-face learning"; and Flavin (2012), indicated how Google and Wikipedia were being used for educational purposes. By 2017, the world of disruptive technologies used in education had developed further with Sagenmüller (2017) predicting that Virtual Reality (VR) e.g. VRChat; collaborative platforms such as Google docs; Augmented Reality (AR) e.g. Microsoft Hololens; and Artificial Intelligence (AI) were the next innovations that would 'revolutionise' learning.

In this paper we look at how it is possible to create engagement and more realistic learning opportunities in agriculture for young people using a combination of disruptive educational technologies - Internet of Things and associated data dashboards, drone design and build and 3D holographic augmented reality (AR) assets - along with a tried and tested educational approach of ‘Active’ Problem Based Learning (PBL) (Schmidt 1983, Wood 2003). 


\section{Disruptive Agricultural Education tools}

\subsection{Internet of Things (IoT) and Data Dashboards}

With the current popularity of Internet of Things (IoT) technology, much research is ongoing in the use of wireless sensor networks in agricultural research studies, (Stoce et al. 2016).

In 2016, Bryceson et al. (2016a) described the development of an IoT multisensory mesh network on The University of Queensland's 1100ha rural campus in SE Queensland, which was set up for agricultural and environmental biophysical data collection in the managed landscape, primarily for educational purposes. A multifaceted web-based interface to the real time streaming IoT data, and problem based learning modules using the data (Figure 1) have also been developed to produce more engaging and active learning based teaching tools.

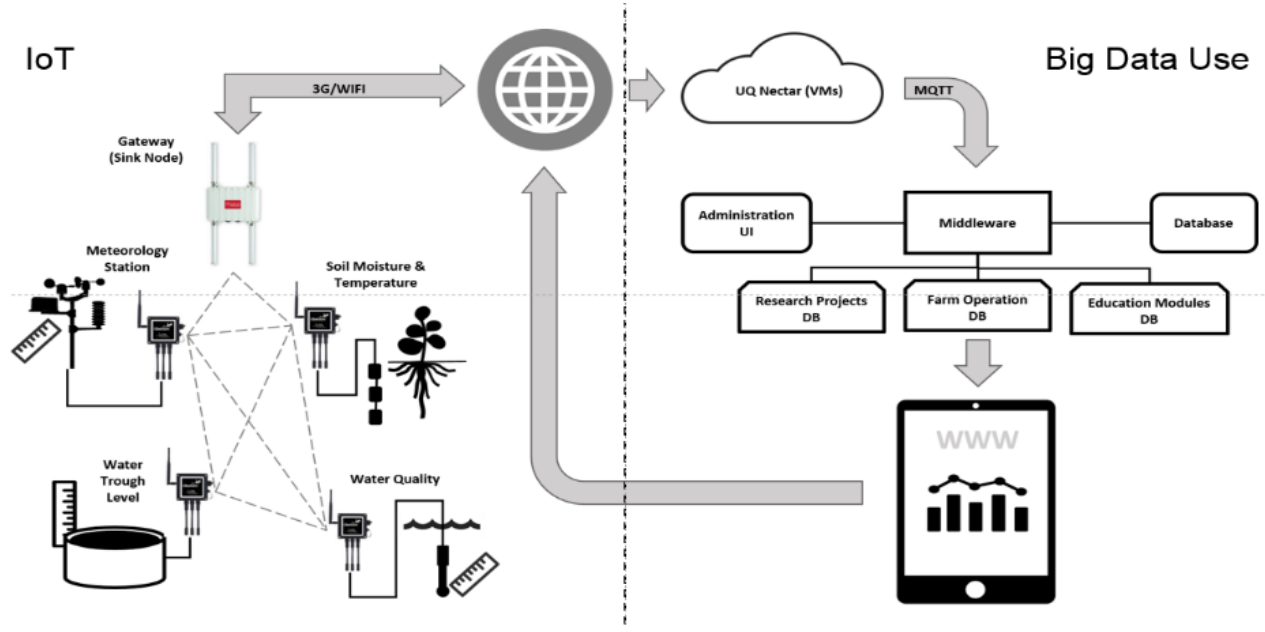

Figure 1. UQGatton IoT multisensory mesh network development and big data use in 2017

The existing applications include a generic data dashboard app to visualise sensor data in real-time via charts and a mapping tool, and a number of other elearning applications which can provide course focused visualisations and assessments. As part of the dashboard app, users have the option of downloading raw sensor data (e.g. in CSV format) for use with external applications such as Excel or the statistics package ' $R$ '. Further development in 2018 has included a Dairy Dashboard app where management data from the UQ Dairy has been included to enable managers and students to visualize the dairy data to ensure that the dairy is performing appropriately against industry benchmarks.

\subsection{Drone Design \& Build}

The use of satellite data or airborne data has been used in agriculture for many years (Kauth \& Thomas, 1976). This type of data has primarily been seen as a useful way of collecting 
spatial variability information covering many hundreds of hectares at a time in order to manage crops, pests, livestock and water more efficiently (Houston \& Hall, 1984; McVicar \& Jupp, 1998). Unfortunately the cost of acquisition and processing of this type of remotely sensed data has proven prohibitive to most agricultural managers in the past who have also had the difficulty of finding adequately trained staff.

However, in the last 5 years much satellite data can now be obtained free through NASA https://earthdata.nasa.gov/ although the issue of resolution and useful (for agriculture) revisit frequency remains. During the same timeframe, there has been an exponential growth in the miniaturisation of electronic componentry which has driven the development and use of small drones (Wang \& Tian, 2011). These drones have been mainly multirotor or fixed wing machines, flying with sensor payloads that can obtain low cost imagery at useful revisit frequencies (Anderson, 2014). Such data can then be processed with readily available software on current hardware. Availability of skilled personnel to do the work is still an issue.

At UQ this lack of skilled personnel is being addressed through the establishment of an Agricultural Remote Sensing Lab, and the development of a third year course in Precision Agriculture. Undergraduate students taking the course, or who are doing an internship or summer research project, as well as postgraduate research students, are all able to make use of the Lab to actively learn to both design and build drones.

In design and build projects students engage in what is regarded as an active learning process (Prince, 2004) - often called 'learn by doing' (Harvard, 2014) - which takes place in the Laboratory and/or field. The learning process is then brought to a close with the creation of a small report outlining the project specifications, the design and build process undertaken, and the implementation of the drone in a real life project, making explicit the internalized knowledge obtained through the process (Smith, 2001).

A number of these drone design and build projects and resultant student engagement, are described in Bryceson et al. (2016b). The UQMiniAg drone (Figure 2) is the most recent addition to the UQGatton drone 'fleet' and has been designed as an aggregate from the collective experience on drone development from research applications. It balances the capabilities of bigger drones, autonomous mission planning and camera payload, but comes with the 'comfort' of a smaller size.
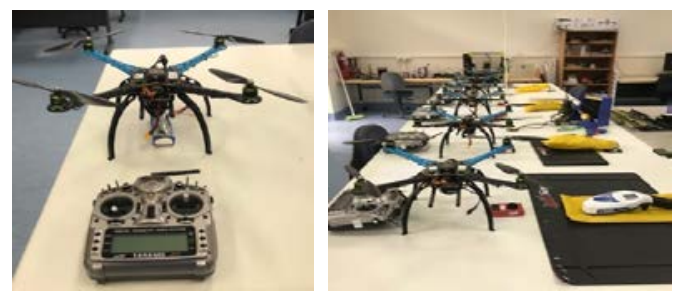

Figure 2. UQMiniAg Drone 
The size and weight of the drone $(<1.3 \mathrm{~kg})$ allows multiple units to be deployed in a dedicated carrying case, simplifying the use of the drones for practical labs performed under field conditions. In addition, the machine size reduces the risk of any injury should students lose control of it, by using lower torque engines. With the standard virtual fence and return to launch safety features, the unit can also be adjusted to 'tame' its acceleration curve and limit its operational range effectively reducing risk associated with its kinetic and potential energy.

The UQMiniAg Drone was developed to work in conjunction with a Raspberry Pi NoIR filter camera that enables imagery in three bands: red, near infra red (NIR) and blue, to be captured. This imagery enables basic remote sensing training to be undertaken by introducing students to the use of reflected light from the earth's surface as a proxy for vegetation stress or vigor. The Normalized Vegetation Index (NDVI) (Tucker, 1979), is taught using imagery taken from a drone mission flown by the student. NDVI gives an index of vegetation greenness or health using the red and NIR wavelengths which can be converted to a stocking rate appropriate for a paddock based on vegetation health. (Figure. 3 below).

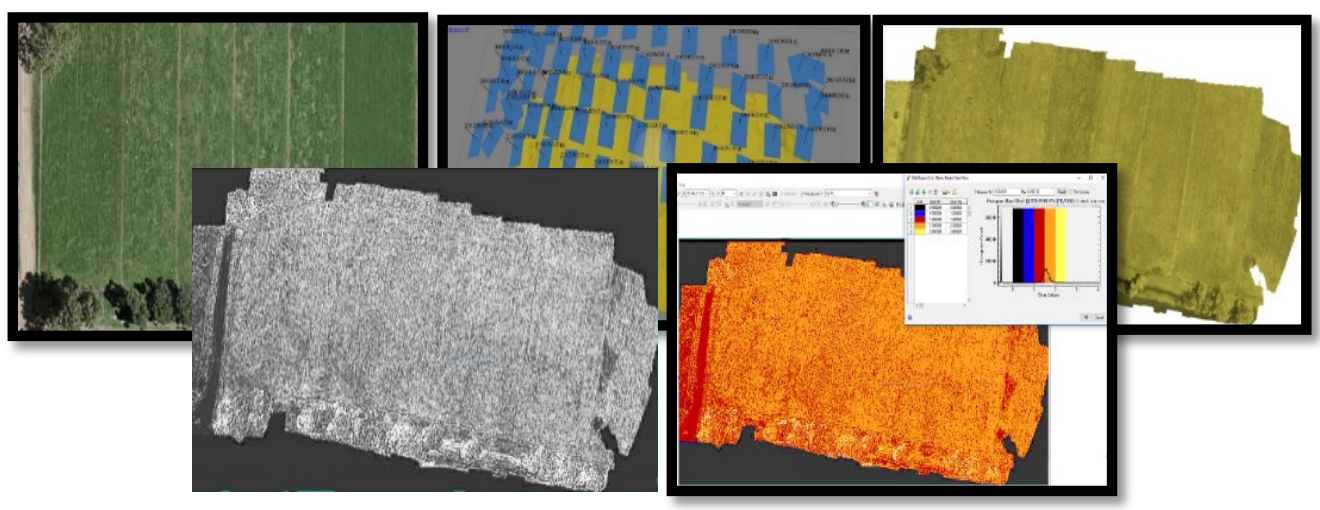

Figure 3. (i) Red Green Blue (RGB) Image captured using drone and NoIR camera, (ii) Multiple images mosaicked to form a single large image, (iii) Raw NoIR camerdata, (iv) Raw NoIR data processed for NDVI (light pixels maximal vegetation) and (v) Stocking rate capacity (1-2 animals/ha ) mapped for paddock.

This type of active learning in multidisciplinary domains empowers the student to not only learn how to use the future tools of their trade, but it also teaches this within context of management decision making on farm, avoiding the all too common complaint by students of “Why I am doing this?”. In Semester 1, 2018 (Feb-June), 42 students participated in the Precision Agriculture course - all flew one of the drones and processed the data as explained. Very strong positive responses to the 'Drone Assignment' were expressed despite it being a technically challenging piece of assessment. 


\subsection{Augmented Reality(AR)}

Schueffel (2017) defines AR as being "a direct or indirect live view of a physical, real-world environment whose elements are 'augmented' by computer-generated perceptual information, ideally across multiple sensory modalities, including visual, auditory haptic (touch), somatosensory (sensation), and olfactory (smell)” (Schueffel, 2017, p. 2).

AR in education is still new and relatively untested. Bryceson et al. (2018) provide a comprehensive review of AR in education to date with published research indicating that AR accelerates engagement with students and engagement of students with the content particularly when theoretical knowledge is not enough to obtain proper skills in professional areas.

A pilot project was undertaken in 2018 to develop a PBL based AR Application (Affluent Effluent) to investigate the feasibility of using Microsoft Hololens technology for teaching in the environmental and agricultural space. The aim for the project was to test student engagement with the technology and appropriate subject matter (in this case waste water management), through using Microsoft's augmented reality technology, the Hololens (https://www.microsoft.com/en-au/hololens), and to also test the use of technology and model/simulation for learning about the issue.

The AR app development process is documented in Bryceson et al. (2018) but from a teaching perspective, the AR asset had to have appropriate visualisations to create an interesting learning environment both above and below water. From a learning perspective, the AR simulation needed to let students achieve the learning objectives of the simulation, by linking to an assignment associated with the content. The assignment could then enable a judgement to be made around the student's ability to identify the problems from the simulation, understand the broader issues relating to these problems, and be able to make recommendations for fixing the problem. A $100 \%$ response rate for an informal evaluation of the Pilot $(n=11)$ for "Strongly Like" to all 5 questions relating to the AR tool's engagement and interest questions, was received when the Pilot App was run with a group of students. Further refinements of the AR app have taken place in 2018 with formal evaluations undertaken in early 2019 which will be discussed at oral presentation.

\section{Conclusions}

All three projects developed and used disruptive technologies for agricultural teaching. They have all proven to engage students with the technology, and with subject matter. They have all taken considerable resources (both human and financial) to achieve, which needs to be further investigated on a cost/benefit basis for any scaling up. A further finding from all the projects is that there is a need for professional development of lecturers and facilitators in 
designing the way such technologies can be used in a class and how appropriate assessments can be developed, which are important in contributing or otherwise, to their success.

\section{References}

Anderson, C. (2014). Relatively cheap drones with advanced sensors and imaging capabilities are giving farmers new ways to increase yields and reduce crop damage. MIT Technical Review, April 232014 - Accessed May 172016 at: https://www.technologyreview.com/s/526491/agricultural-drones

Archer, W., Garrison, R \& Anderson, T. (1999). Adopting Disruptive Technologies in Traditional Universities: Continuing Education as an Incubator for Innovation, Canadian Journal of University Continuing Education, 25(1), 13-30.

Bryceson K.P., Navas Borrero, A., \& Gunasekera K. (2016a). The Internet of Things (IoT) Smart Agriculture Education at The University of Queensland. Proceedings of EDULEARN16, 8th International Conference on Education and New Learning Technologies, 8036-8044, Barcelona, Spain, July 2016.

Bryceson K.P., Navas Borrero A, Camilleri, C, \& Vasuian, F. (2016b). Small Quadcopter Drones as Educational Tools in Agriculture at The University of Queensland, Australia. Proceedings of EDULEARN16, 8th International Conference on Education and New Learning Technologies, 8052-8060, Barcelona, Spain, July 2016

Bryceson, K.P. and Yaseen, A. (2018). Disruptive Technologies and the Agrifood Industry: Fit for Practice? In E-Business and Supply Chain Integration: Strategies and Case Studies from Industry, Ozlem Bak, (Ed.), Ch 2, 27-46, UK/USA: Kogan Page Ltd.

Bryceson K.P., Vallely, E., Vasuian, F. (2018) Affluent Effluent Waste Water Management - a Pilot Project using Augmented Reality for student engagement in agricultural education. Proceedings of EDULEARN18, 10th International Conference on Education and New Learning Technologies, 5751-5760, Palma, Spain, July 2018.

Bryceson, K.P. (2006). 'E’ Issues in Agribusiness: The What, Why, How. 384pp. UK: CABI International Publishing.

Christensen, C. M. and Overdorf, M. (2000). Meeting the challenge of disruptive change. Harvard Business Review, 78, 66-76.

Flavin, M. (2012). Disruptive Technologies in higher education, Research and Learning Technology Supplement: ALT-C 2012 Conference Proceedings, 20, 102-111, Available at: http://dx.doi.org/10.3402/rlt.v20i0.19184

Garrison, D.R. and Kannuka, H. (2004). Blended Learning: Uncovering Its Transformative Potential in Higher Education, Internet and Higher Education, 7 (2), 95-105.

Gunasekera, K., Navas Borrero, A., Vasuian, F. \& K.P. Bryceson (2018). Experiences in building an IoT infrastructure for agriculture education, Procedia Computer Science (2018), 155-162. doi: 10.1016/j.procs.2018.08.161

Harvard, J. (2014). Learning by Doing. Harvard Magazine, 8-20, May-June, 2014.

Houston, G. and Hall, F.G. (1984). Use of satellite data in agricultural surveys, Communications in Statistics - Theory and Methods. 13(23), 2857-2880. Available at: http://dx.doi.org/10.1080/03610928408828868 
Kauth, R. J. and Thomas, G. S., (1976). The Tasselled Cap. A Graphic Description of the Spectral-Temporal Development of Agricultural Crops as Seen by LANDSAT (1976). LARS Symposia. Paper 159. Available at: http://docs.lib.purdue.edu/lars_symp/159

Lehmann, R.J, Reiche, R. \& Schiefer, G. (2012). Future Internet and the Agrifood sector: state-of-the-art in literature and research, Computers and Electronics in Agriculture, 89, 158-174.

McVicar T. and Jupp, D. (1998). The Current and Potential Operational Uses of Remote Sensing to Aid Decisions on Drought Exceptional Circumstances in Australia. Agricultural Systems. 57(3), 399-368.

Millar, C., Lockett, M. \& Ladd, T. (2018). Disruption: Technology, Innovation and Society, Technology Forecasting and Social Change, 129, 254-260.

Prince, M. (2004). Does active learning work? A review of the research. Journal of Engineering Education, 93(3), 223-231. Full text available through MIT Libraries

Sagenmüller, I. (2017). 4 Disruptive Education technologies poised to change higher learning. Available at: https://www.u-planner.com/blog/disruptive-educationtechnologies-poised-to-change-higher-learning.

Schmidt, H.G. (1983). Problem-based learning: Rationale and description. Medical Education, 17, (1), 11-6.

Sharples, M. (2003). Disruptive devices: mobile technology for conversational learning. International Journal of Continuing Engineering Education and Lifelong Learning, 12(5/6), 504-520.

Stočes, M., Vaněk, J., Masner, J. and Pavlík, J. (2016). Internet of Things (IoT) in Agriculture - Selected Aspects, AGRIS on-line Papers in Economics and Informatics, 8(1), 83 - 88. doi: 10.7160/aol.2016.080108.

Tucker, C. J. (1979). Red and photographic infrared linear combinations for monitoring vegetation, Remote Sensing of the Environment, 8, 127-150.

Wang, H. \& Tian, L. (2011). Development of a low-cost agricultural remote sensing system based on an autonomous unmanned aerial vehicle (UAV). Biosystems Engineering, 108(2), 174-190.

Wood, D. (2003). Problem Based Learning. In: Cantillon, P.; Hutchinson, L. and D. Wood (Eds) ABC of Learning and Teaching Medicine, Ch 3, 8-11. London, UK: BMJ Publishing Group. 